\title{
Older, Greener, and Wiser: Charting the Experiences of Older Women in the American Vegan Movement
}

\author{
Abstract \\ Vegan feminist theory argues that women and other marginalized groups experience \\ discrimination in the vegan movement given its failure to apply intersectional praxis. We \\ interviewed a small sample of older vegan women in America, hypothesizing that they \\ would report feeling particularly vulnerable to discrimination given the vegan \\ movement's patriarchal leanings and its heavy focus on health and vitality. Our results, \\ however, are mixed. Some viewed older age as an asset that strengthened their ability to \\ commit to veganism, while others reported stressed social interactions, \\ underrepresentation in the movement, and lack of support by doctors.
}

\section{Keywords}

Age, Ageism, Animal rights, Gender, Identity, Social movements, Veganism, Vegan Feminism 


\section{Introduction}

In this study, we examine the oft overlooked experiences of older ${ }^{1}$ women who are active in the American vegan movement. Veganism is a means of living which rejects the use of animal products. $^{2}$ The reasons for doing so are many, but most often relate to animal ethics, environmentalism, or personal health (MacNair, 2001). Although the vegan movement got its official start with the forming of The Vegan Society in 1944 Britain, it is only recently that it has been studied scientifically. American researchers in the $21^{\text {st }}$ century, for instance, examine the various structural barriers which vegans must negotiate as they advocate plant-based eating for reasons of personal and public health (Cherry, 2006; Gaarder, 2011; Harper, 2010; Wright, 2015). Although these researchers have considered the nuances of race, gender, and nationality politics in shaping vegan activism in America, exceedingly little attention has been paid to the importance of age to the activist identity. This is a particularly interesting oversight given that the American vegan movement is comprised of approximately $80 \%$ women (Gaarder, 2011), but it also characteristically promises youthfulness and healthfulness in its campaigning. ${ }^{3}$ What does it mean to be an older woman in a consumption-based movement that presents veganism as the antidote to illness and aging?

Vegan movement scholars repeatedly emphasize the importance of inclusivity to the vitality of the movement as a matter of social justice (Harper, 2010; Ko and Ko, 2017; Wright,

\footnotetext{
1 "Older" is a term advanced by Applewhite (2016) to emphasize that age is a relative status.

${ }^{2}$ The Vegan Society (n.d.) defines the practice as an effort to "exclude - as far as is possible and practicable — all forms of exploitation of, and cruelty to, animals for food, clothing or any other purpose."

${ }^{3}$ By way of an example, the American vegetarian movement experienced nothing short of a crisis when its famous founder Sylvester Graham died in his 50s after a lifetime of disability and poor health. Fearful that his demise might undermine the movement's celebration of vegetarian vitality, movement leaders worked to tarnish Graham with accusations that he had overworked himself and cheated on his regimen (Shprintzen, 2013). From the movement's inception, vegans and vegetarians have been expected to age both well and productively as representatives of the cause. Plant-based diets were billed as a more efficient intake of nutrients that were uniquely capable of producing hard-working, physically superior specimens. The inevitability of old age could sometimes confound this claimsmaking.
} 
2015), but inclusivity might also act as a strategic benefit. As is true of many social movements (McHugh, 2012; Sawchuk, 2009), veganism relies on the support of olders who are more likely to have the time, skills, and resources available to participate. The Vegan Society also recognizes olders as important financial donors (Rodger, 2002). However, the vegan movement must also contend with the prevailing belief that veganism lacks joy and sustenance. Given stereotypes that pit vegans as sickly and negative (Cole \& Morgan, 2011; Markowski \& Roxburgh, 2019), vegan frames glorify physical wellbeing to counter disparaging stereotypes and secure cultural validation (Freeman, 2014). This frame is keyed to resonate with Western culture's veneration of youth and vilification of age (Vasil \& Wass, 2006), but, in doing so, it could be putting olders (who are stereotyped as weak and unwell) in a precarious position. Aging, furthermore, is a gendered experience. Because women's social status is linked to their sexual availability, women beyond childbearing years are burdened with perhaps the greatest share of age-based discrimination (Holstein, 2015). We suspect that this difficulty is only amplified in the American vegan movement since, in addition to its youth- and health-focused claimsmaking, it also attempts to resonate with patriarchal Western culture with the regular deployment of sexist frames (author's research here). This sexist strategy persists in spite of its quite heavy reliance on women's volunteer labor.

Despite several decades of theoretical inquiry in the area of ecofeminism (Adams \& Gruen, 2014; Gaard, 1993; Harper, 2010; Ko and Ko, 2017; Pendergrast, 2014) and the growing interest in pro-intersectional politics in Critical Animal Studies and activist dialogue (Twine, 2010; Wright, 2015), there has been surprisingly little research on the topic of aging and femininity. In this article, we present findings from an exploratory qualitative study extracted from a small sample of older women $(n=20)$ who identify with the American vegan movement. 
We focus on their sense of self and belonging, documenting how they do (or do not) negotiate their multifaceted identities given the complex and sometimes competing social expectations presented by both the vegan and nonvegan cultures which they inhabit. In some cases, the movement appears to buffer them from the strains of living vegan in a nonvegan world. In other cases, the vegan movement challenges their sense of belonging with regard to the limited age diversity it exhibits. Some women also report that their gender predisposes them to empathize with other animals and thus associate with the movement. For many, however, just how all of these variables coalesce is not especially considered. The intersection of age, gender, and vegan activist, in other words, is a complex one which evades clear categorization. With so little research on the topic of aging in social movement communities and with activists themselves unclear on the matter, this study relies on vegan feminist theory to tentatively map this multidimensional intersection.

\section{Literature Review}

\section{Vegan Feminism}

As previously discussed, there has been increasing disciplinary interest in understanding the diversity of experiences in the vegan movement. Indeed, vegan feminism (Adams \& Gruen, 2014; Harper, 2010; Ko \& Ko, 2017) argues that a flat, single-issue approach to interpreting (and resisting) the oppression of Nonhuman Animals ${ }^{4}$ ultimately fails to recognize the entangled nature of structural violence. As such, it is thought that the movement lacks a coherent plan for advancing social progress and cannot properly support a diversity of participant and nonparticipant identities affected by movement processes.

Some research has tested the veracity of vegan feminist theory, offering evidence to

\footnotetext{
${ }^{4}$ This term is capitalized as a measure of respect to denote their status as a distinct demographic identity.
} 
support these claims. Psychological surveys, for instance, demonstrate a link between gender, personality formation, and speciesism (Graça et al., 2018). That is, the social dominance trait associated with masculine socialization and the high levels of empathy associated with feminine socialization account for gender differences in perceived relationship to other animals. Likewise, researchers find a positive correlation between anti-speciesist and feminist attitudes in women (Allcorn and Ogletree, 2018). Sociologists, too, have identified through qualitative research a strong theme of feminist solidarity with other animals (Taylor and Fraser, 2018). The entanglement of gender and species oppression has also been evidenced in content analyses of mass media whereby women are diminished by being likened to Nonhuman Animals (Adams, 2003) and boys and men who fail to achieve masculine gender norms are diminished by being described as effeminate plant-based consumers (Gambert and Linné, 2018).

\section{Older Vegans}

Given these connections, vegan feminism has petitioned the vegan community to expand its circle of compassion beyond Nonhuman Animals to include marginalized humans as well. Yet it has not yet developed a substantial credo on the role that age plays in these entanglements. This oversight is problematic most fundamentally because the motivations for older vegans are often distinct from that of youngers. Many adopt a vegan lifestyle to alleviate increasing health concerns, while other olders will have had more opportunities to be exposed to persuasive, behavior-changing phenomena across their lifetime. Although the most common motivator relates to a desire for ethical alignment (Janssen, Busch, Rödiger, \& Hamm, 2016), others, especially older persons, are more likely to go vegan for health reasons (Asher, Green, Gutbrod, Jewell, Hale, \& Bastian, 2014; MacNair, 1998). ${ }^{5}$

\footnotetext{
${ }^{5}$ This is not to stereotype older vegans as only health-focused since many older vegans also adopt veganism out of
} 
Vegan demographic research in the United Kingdom and the United States supports that olders are in the minority (The Vegan Society, 2016; Vegetarian Resource Group, 2016), and this minority status likely lowers their level of priority in social science research. The Vegan Society, the movement's progenitor, has conducted some rudimentary surveys of older members which provide some indication of what interests and challenges older vegans (Henderson, 2011; Henderson 2012). However, this research focuses primarily on lifestyle issues related to product availability and social integration, and it does not explore olders' experiences within the vegan community per se. The Vegan Society's findings suggest that the concerns of older vegans are rather similar to that of younger vegans (i.e., they have difficulty locating vegan alternatives) and older nonvegans (i.e. they are vulnerable to isolation). Yet, most vegans must cope with some element of isolation, older or not, due to their deviant dietary identity (Bresnahan, Zhuang, \& Zhu, 2016; Markowski \& Roxburgh, 2019; Twine, 2010). The Society's co-founder, Donald Watson, who remained active with the organization well into old age, did hint at the possibility that olders were excluded given that contemporary issues of The Vegan (one of the movement's leading publications) were difficult to read with aging eyes (Rodger, 2002). Otherwise, the experience of olders in the vegan community is relatively undocumented.

In addition to being underserved by research, the tendency for doctors to engage in age and gender discrimination (Hamberg, 2008; Reyna, Goodwin, \& Ferrari, 2007) suggests that vegan olders are likely disadvantaged in healthcare access. Research finds that many doctors do not treat their older patients or female patients with as much respect, patience, or responsiveness as they afford to others. Older women, who experience the double jeopardy of agedness and femaleness, are especially vulnerable (Chrisler, Barney, \& Palatino, 2016; Henderson, 2008; 
Sharpe, 2008). For patients living in home or institutional care, there is also concern over vulnerability to abuse. All olders face challenges in such situations, but lack of dietary independence is a unique vulnerability for vegans and vegetarians. Vegetarian for Life, for instance, an organization which addresses the needs of older vegetarians and vegans who require living assistance, reports that patients are sometimes fed animal products under an assumption of ignorance and that it is in their best interest (Corbett, 2014) (Figure 1).

The Vegan Society has recognized that aging with dignity is especially difficult for vegans and has devoted resources to assisting older vegans since its formation, in one case raising funds to launch an all vegan retirement home. More recently, it collaborates with hospitals, care homes, lunch clubs, and meal delivery services to serve aging vegans (Henderson, 2012). Like Vegetarian for Life, The Vegan Society has since turned to fighting elder abuse in caretaking. To legitimize its campaigning effort to change public policy, it has employed a prointersectional strategy that highlights the shared difficulties between nonvegans affiliated with minoritized religions and vegans, both of whom share similar dietary restrictions (Clark, 2005). Until medical institutions are able to respect the autonomy of older vegans and engage in the necessary research, these charities offer vital social services for an otherwise overlooked demographic.

\section{Intersectional Failure}

Compounding this overall lack of attention to older vegan demographics, the vegan movement's penchant for vitality claimsmaking creates additional opportunity for what Kimberlé Crenshaw (2016) refers to as "intersectional failure," defined as a lack of movement attentiveness to intersecting oppressions in its field of interest. This failure as it relates to aging and veganism is gendered given the disproportionate pressure on older women to age "well." 
Crenshaw notes that social movements too often lack an awareness to the shared mechanisms of oppression that motivate various social justice causes. For instance, recent racial justice activism, she has observed, lacks a solid feminist praxis and thus prioritizes police violence against men of color to the effect of underserving women and girls who frequently experience this violence in a sexualized manner. Male movement leaders are also more likely to be granted legitimacy, status, and platform both in the movement and its audience despite the disproportionate labor that women have contributed to mobilization efforts and policy change. Other researchers have identified that the Black Lives Matter movement has not attended to issues of aging either, nor has it coped well with intramovement ageism (Reynolds, 2017).

At least some attention, limited though it may be, has been paid to ageism and sexism in neighboring social justice collectives (Foster, 2018; Rupp, 2001; Valiente, 2015), yet scholars have overlooked these processes as they intersect and manifest in the vegan movement. As vegan feminists have documented, it is known that the movement has exhibited intersectional failure in the $21^{\text {st }}$ century on several fronts relating to race, gender, and nationality (Gaarder, 2011; Harper, 2010). Many activists, keen to protect "nonhumans first," resist pro-intersectional analyses (author's citation here), but some emerging nonprofits such as Better Eating International, Direct Action Everywhere, Food Empowerment Project, and Vegan Outreach ${ }^{6}$ and are moving to acknowledge problems with diversity. None of these organizations explicitly acknowledge ageism, but some organizations do cater to older demographics. PETA Prime, for instance, is a subsidiary of the People for the Ethical Treatment of Animals (PETA) which offers activist and nutritional advice, blogs, and a magazine for senior vegans and activists. The Physicians Committee for Responsible Medicine also produces a litany of nutritional publications regarding

\footnotetext{
${ }^{6}$ Vegan Outreach adopted an explicitly intersectional approach following a change in leadership in 2013.
} 
diseases that are more likely to afflict older persons. In fact, we find that when olders are at all acknowledged, health maintenance is the leading age-related issue. Thus, a number of organizations can be said to cater to older vegans, but how older vegans navigate a wider movement culture that is youth-oriented and health-focused is unclear. Indeed, the focus on health remains aligned with ageist expectations that olders sustain vitality throughout their lifespan.

Ageism is also likely to surface from organizational longevity since generational schisms can emerge within those social movements which are fortunate to survive long enough. Older activists who harbor valuable experience and younger activists touting new ideas have clashed in both the feminist movement and civil rights movement, for example (Gordon, 2007; Rupp, 2001). While youth-dominated movement cultures may venerate the wisdom of older activists, their overarching desire to be cutting edge and relevant can encourage ageism. When these stigmatized older activists are also female, their likelihood of being labeled outmoded and irrelevant can only grow. Patriarchal in structure and tactical design (Gaarder, 2010), the American vegan movement's lionized male leaders, for instance, belittle the "little old ladies in tennis shoes" who are thought to comprise the movement's rank and file (Adams \& Calarco, 2017). The suppression of femininity and agedness tactfully dismisses older women in the movement's bid to appear rational, strong, and forceful.

While olders of all genders are prone to experiencing underrepresentation, older women are particularly vulnerable. Mainstream vegan media, such as that dispatched by PETA, regularly sexualize the bodies of thin, young women to solicit public attention and emphasize that veganism can promote a sexually desirable figure (Deckha, 2008; Pendergrast, 2018). Of the 161 
images provided on PETA's "Skins" campaign website, ${ }^{7}$ only two older women were included (neither of whom were pictured naked). A then 62-year-old Oprah Winfrey did appear in one PETA anti-fur ad, but only as a photoshopped prank for an April Fool's stunt (Kretzer, 2016) (Figure 2). The idea of using an older woman's body in the "I'd Rather Go Naked" campaign, in other words, was considered a joke.

\section{Methodology}

Our review of the literature has indicated that demographic data on older vegans is greatly lacking, but given the vegan movement's focus on youth, vitality, and sexuality, vegan feminist theory would suggest that older women likely experience strains in their vegan identity. Lacking a body of prior research to guide our analysis of age and gender as it impacts vegans, we employed an exploratory approach that is based on the tenets of vegan feminist theory (Adams \& Gruen, 2014; Harper, 2010; Ko \& Ko, 2017; Wright, 2015). Semi-structured phone interviews were conducted with twenty American participants over the age of 50 who identify as vegan women. What constitutes “old age," is, of course socially constructed. We targeted women aged 50 and above simply based on existing categorical definitions utilized in the vegan community, namely Adams, Breitman \& Messina's 2014 publication, Never too late to go vegan: the over-50 guide to adopting and thriving on a plant-based diet and PETA's yearly "Sexiest Vegans over 50 " contest.

Although the lack of prior research gravitated us to a grounded approach, qualitative research is typically limited by its reliance on a small sample size. This, of course, poses a problem of the generalizability of our findings. For this reason, we cannot claim that this research sufficiently speaks to the experience of all older vegan women in America, but it does

\footnotetext{
${ }^{7}$ Retrieved March 1, 2018 from https://www.peta.org/category/main-issues/skins/
} 
offer a useful starting point. Our sample was largely based in the Jersey Shore region which is in the vicinity of New York City. Most participants were recruited at vegan community events held in Monmouth County, New Jersey, but additional participants were located through online groups such as Vegan Feminist Network, NJ Farm Animal Save, and Vegans of Central Jersey. Some interviewees were also solicited through snowball sampling and professional networks. The twenty respondents who agreed to participate were interviewed by phone for approximately thirty minutes in the spring of 2017.

In addition to general demographic information, participants responded to open-ended questions on topics related to age and gender within the context of vegan living. Again, these questions were constructed to test the vegan feminist premise that an individual's various identities work simultaneously to shape their social experiences in a society and that this intersection is informed by their relationships with other animals. To this end, we asked respondents why they went vegan, how long they have been vegan, and if their reasons for being vegan has changed over the years (Table 1) with expectations that their veganism is uniquely embodied due to their older age in a youth-oriented movement culture. We also asked respondents about their perceptions of age distribution in the vegan movement, if they felt their age has any effect on how they are perceived within and outside of the vegan community, and whether they believed that older vegan women had access to adequate health resources. We queried our participants directly about the main premise of vegan feminist theory by gauging their consciousness to any connections between their veganism, age, and gender. Lastly, the women were asked if they felt they were appropriately and fairly depicted in the media as older vegan women.

In the scientific study of sociological phenomena, qualitative methodology recognizes 
that social realities are subjectively understood and that lived experience and individual insight can illuminate worlds unknown to the researcher (Seidman, 2013). Subsequently, we strategically ensured that our level of inquiry was sufficiently broad so as to provide our participants with the space to identify what they believed to be most relevant. Following our interviews, recordings were transcribed and coded before we utilized grounded qualitative content analysis to identify key themes. One author undertook the initial coding of the entire dataset, at which point the second author reviewed the coding results and collaborated with the initial author to readjust the coding scheme and results to improve reliability. Because our coding scheme was informed by vegan feminist theory, we paid particular attention to how the marginalized identities of our subjects intersect and express in the various social contexts that they identified (which were primarily the vegan movement, their nonvegan communities, healthcare services, and the American mediascape) as well as their consciousness to this intersectionality.

\section{Results}

Half of the respondents were aged between 50 and 60 years old, $30 \%$ were between 61 and 70 years, and $15 \%$ were between 71 and 75 . The overwhelming majority (at least $85 \%$ ) were white. One participant identified as mixed race, while two chose not to respond. The sexual orientation of most respondents was heterosexual at $90 \%$, with the remaining two respondents identifying as queer and bisexual respectively. Our respondents were well educated, a finding that supports demographic research of older activists associated with other leftist movements (Adler, Schwartz, \& Kuskowski, 2007). One person held a high school diploma only, one third held a bachelor's degree, $30 \%$ had some college education, $25 \%$ held a master's degree, and the remaining participant held a Ph.D. The level of annual income varied somewhat but supports 
previous research that pits vegans as middle-class (Maurer, 2002). Twenty percent received between $\$ 100,000$ and $\$ 300,000,35 \%$ brought in between $\$ 20,000$ and $\$ 100,000$, and the remaining $40 \%$ had access to less than $\$ 20,000$ a year. ${ }^{8}$ Although the latter $40 \%$ might be considered lower income, they did have other forms of support and the majority of the sample can be said to be middle to upper-middle class. Only one third of our respondents received financial assistance such as social security, pension, or disability.

The majority of women in the study had been vegan between 6 months and 5 years (45\%). Forty percent had been vegan between 6 and 10 years, while the remaining $15 \%$ were long-term vegans of 11 years or more. Although there were some outliers, we found that respondents with higher socioeconomic statuses had longer vegan careers (about 10 years), while those with lower socioeconomic statuses averaged a vegan career of just 4.7 years. ${ }^{3}$ Most women made the switch to veganism later in life between the ages of 41 and $50(35 \%)$ or 51 and 60 (40\%). A few made the switch under the age of forty (15\%) and over the age of $60(10 \%)$. The majority of women in this study $(75 \%)$ were vegetarian for some time before becoming vegan.

The majority (70\%) cited concern for Nonhuman Animal wellbeing as their primary motivation, which conflicts with existing research that cites health as a primary motivator for older vegans (Asher et al., 2014; MacNair, 1998). For remaining participants, motivations consisted of a medley of concerns with environmental degradation, health, body image, and family influence. Of the women who were influenced by ethics, six mentioned that learning about the dairy industry through media was particularly moving to them. There was little fluctuation in motivation over their vegan careers. Most ethical vegans reported that their current

\footnotetext{
${ }^{8}$ Data was missing for the remaining $5 \%$ of respondents. Due to a methodological flaw, participants were not asked to clarify specific earnings between $\$ 20,000$ and $\$ 100,000$.

${ }^{3}$ Statistic omits outliers.
} 
concern for Nonhuman Animal wellbeing remained the primary reason for their sustained veganism, although five did concede that other motivations had grown to motivate them over time as well. Only two participants acknowledged that their initial motivation of health and family influence been replaced by concern for Nonhuman Animals. While the predominant motivation for our older vegans was based in animal ethics, it should be noted that the recruitment strategy may have biased the results in this regard since some of the New Jersey events and organizations we targeted were oriented toward Nonhuman Animal rights.

\section{Discussion}

Age Representation in the Vegan Community

One key theme that emerged from our interviews was an awareness (or lack thereof) to age difference. Participants were asked to share their thoughts on age distribution and the visibility of women like themselves in vegan spaces. Half observed that the movement was comprised mostly of younger people. A quarter of participants felt that the movement contained a mixed age range, while remaining participants thought that olders dominated. Explains one woman, "There seems to be kind of two lumps to this curve, one is of aging hippies and one is of millennials." Explanations for this gap were generally not forthcoming, although one participant did offer some insight:

It seems like there are a lot of people who are between the 16-23 age who are experimenting and finding their way and trying to see if this is something that fits $[\ldots]$

a lot of those people maybe sort of lapse from maybe peer pressure and whatever else and go back to eating meat and then a lot of people now in vegan circles are a little older. In their 40s to 50s age range because it's like we kinda figured out, "Okay this is what works for us." So, a lot of people that I know now are newer vegans, even though a lot of 
us have been vegetarian for a long time, it's really important for us to completely take out all animal products out of our diet.

This respondent's observations suggest that different roles are available to older vegans and younger vegans with the predominance of younger vegans attributed to the experimental nature of young people, not the disinterest of olders. Although most respondents believed the movement to be dominated by younger persons (and this observation is supported by the afore cited survey research conducted by The Vegan Society), the possibility that olders engage (or believe that they engage) in a wiser, more steadfast type of veganism is an interesting reversal of behavioral stereotypes. This perceived disconnect across generations and variation in motivation has also been reported by older activists in the feminist movement (Rupp, 2001) and the Black Lives Matter movement (Reynolds, 2017). Vegan feminist Audre Lorde (2017) has observed this disconnect as well, emphasizing the corrosive nature of ageism on collective solidarity. According to Lorde, ageism is a tool of the oppressing classes which has been unwittingly and imprudently employed by anti-oppression advocates.

We also queried participants as to their perceptions of media diversity with regard to both vegan-produced media and vegan representation in mainstream culture. The majority felt that neither space adequately represented their demographic. One participant expressed: “They don't depict people like me, I am not acceptable in anything [ . . . ] I am not desirable until maybe like I am 70 and I still look like I am 50, then maybe they will flaunt people like myself and try to sell some kind of product." Indeed, this participant's feelings were rather representative of the sample. Thirty percent also felt that older vegan women were not visible unless the intention was to sell something, usually drugs or supplements. As one respondent explains, "My age is not represented in anything except ads for drugs y'know, heart disease or whatever." Thus, on one 
hand, lack of representation aggravates ageism in rendering olders invisible, but, on the other hand, what representation is produced reinforces limiting expectations that olders must "age well” (Angus \& Reeve, 2006; Katz \& Laliberte-Rudman, 2004). Drug adverts aside, most respondents believed that vegan media frequently linked veganism with youth and thinness. Numerous participants expressed frustration with this limited framework: "It's not fair that we are supposed to be physical specimens that are superior to somebody else our age because most of us are doing this for ethical reasons." In the few instances that older vegans are represented, participants noted that they were usually bodybuilders or other fitness gurus which exclude women given the male dominance in these fields.

Interviews reveal an understanding that there is a privileged "look" or physical appearance required for vegan representation. This look is one that does not work in the favor of older vegan women who are not involved in health promotion or do not appear young for their age. This young, thin-centric narrative is amplified in social situations as one woman explained regarding the difficulty she faced in having her choices being accepted by family:

They still have different viewpoints about what health means, and they are not convinced that eating this way is healthy for me and because I happen to be large that kind of hurts it more for them, I think. "Well if she's vegan but she's fat then maybe it's not that good for her.” And they don't really understand the why and they're not really interested in knowing the why, so that aspect is unfortunate.

Despite stereotypes promulgated by veganism and mainstream media, veganism is not necessarily a path to weight-loss. Vegan bodies are diverse in size and shape just as are nonvegan bodies (author's citation here). For ethically-minded vegans, the movement-wide projection of highly restrictive and stereotypical identities can become frustrating barriers to the 
altruistic work they see themselves as engaging. Furthermore, older persons, especially women, are regularly subjected to patronizing communication from care givers and loved ones (Draper, 2005, Hummert, Shaner, Garstka, \& Henry, 1998), such that it would be expected that vegan olders (who defy convention in dietary practice) would experience resistance in their care networks, too.

\section{Boundary Setting}

Most participants recognized an age disparity in the vegan subculture, but their responses indicate an underdeveloped consciousness as to how this might impact their integration within vegan spaces and nonvegan society at large. Most of the women had difficulty connecting their age and gender identities to their vegan experiences, but a few correlations were offered. First, many of the women had restrictions on the type of activities they would engage in and were careful of the company they kept. Some women explained that they only socialized with other vegans due to the judgment they received for their choices by nonvegans. For example, one participant remarked: "People are intolerant about it and are rude and make nasty comments [ . . ] I would rather go out with vegans than nonvegans." Our participants felt that they received the most resistance from family members. Most vegans experience strained social relationships (Twine, 2017), but this may be intensified for older persons whose status and authority wane as they age. For the nonvegans in our participants' social networks, our participants' veganism could be interpreted as evidence to declining independence and effective decision-making. As one woman expresses:

Sad to say I have found as a middle age and late age adult that I still receive dismissive and trivializing reactions from people in social situations, primarily family. A little less so in non-family social situations, but I think the reason for that is that I spend almost all 
of my time with other vegans socially.

Such pushback experienced by respondents ranged from teasing over holiday dinners to overt criticism about their health and wellbeing.

The criticism these women receive from those close to them, coupled with the ethical disconnect they feel from nonvegans, motivates them to erect social boundaries in their lives. Doing so allows the women to protect their independence and solicit respect. These boundaries structured how the women spend meal times and what products they permit in the home:

I will choose the restaurant and it will be one with vegan options. And I've, over the years, on and off, rent out my basement rooms when I need extra income and that whoever was down there always knows I'm vegan and if there is ever food cooked up there in the upstairs kitchen it cannot contain any animal sourced food.

Others have been so affected that they cannot handle being in nonvegan environments, "I don't go places unless I really don't have a choice. I won't even sit down with people who are eating meat." For some, this boundary work necessitated a search for new, more accepting communities after having received so much hostility regarding their lifestyle choices. For one participant, criticism from others, in this case their church congregation, even impeded their spiritual life: They behaved reprehensibly, very inappropriately. It was ironic because they tended to promote themselves as an inclusive church community. So, after that really awful experience, and a community that I had been a member of for 15 years, we [ . . ] stopped going $[\ldots]$ and we started going to another church.

These comments indicate that many of our respondents experience the most difficulty from nonvegans, forcing them to seek refuge in vegan communities. Thus, while vegan spaces appear to underserve older women in leadership opportunities and representation, they nonetheless 
provide an important buffer to an often hostile nonvegan society. Feelings of rejection and tension with nonvegans are common to vegans of any age, however, and we could not identify among our participants much concern with ageism in the context of vegan living. Nonetheless, it can be ascertained that dissolving relationships with friends, family, and church can be especially problematic for older persons, particularly as they are disproportionately vulnerable to isolation and loneliness in Western cultures.

\section{Veganism as Gendered}

While the participants had difficulty pinpointing the effect that their age had on their experience of veganism, there was a stronger understanding as to the influence of gender. Many respondents rightly identified that vegans are disproportionately female. For some, this was attributed to the relational roles and compassionate decision-making that are expected of women but stigmatized for men. As one participant explains: "I just think that women are allowed to be softer. And we're allowed to love animals and that sort of thing, in a way that men traditionally

have not been allowed. But I do think it is easier for women to be vegan and that's why there are so many more of us." Others took this correlation further, offering insight as to how feminism and Nonhuman Animal rights intersect:

I think it's easier for women to be more sympathetic, empathetic, or can relate or identify with the oppression of animals, particularly with the ag [agricultural] industries because of the experiences: the exploitation, the objectification, the control of the female reproductive experience/biology. So, I can kind of relate to that, I have been a victim of sexism, even sexual assault. I think that undeniably colors, even at a conscious level not just a subconscious level, the profound feeling of [ . . . ] anguish I have for female nonhuman animals that are commodified. 
This feeling of discomfort regarding the violation and commodification of the female reproductive system in animal agriculture, specifically in terms of the dairy industry, was a common one in our sample. Nearly one third of participants referenced it as an influence on their decision to go vegan. Having themselves labored for several decades in reproductive roles in a society that places little value on feminized work, they seem to sense a camaraderie with other female-bodied animals.

\section{Health Access}

Although we prioritized the vegan movement as the primary location for the intersectional failure we predicted, we thought it relevant that older women might face difficulty outside the bounds of their movement as well. Veganism is unique as a social movement in that it requires adherents to modify how they nourish their body. For this reason, it is important that health resources are available and accessible. When participants were asked about the health resources available for women their age who were pursuing veganism, they referenced online nutritional information and vegan or vegan-friendly physicians. Two thirds of our participants believed that physicians were generally supportive of veganism. Participants rightly assumed that healthcare disparity certainly existed for vegans whether or not they personally experienced it. They pointed to the importance of living in a larger city advantaged by more knowledgeable and accepting practitioners (since so many of our respondents lived near New York City, this likely privileged their access to accommodating doctors). Other women, however, did contend with resistant medical practitioners. One recounts: “[Doctors will] fight [acquaintances who are my age] if they don't want to eat meat, you know and [the doctors think they will] be unhealthy which is the complete opposite of reality." Recall that physicians, influenced by age and gender prejudice, may sometimes provide patronizing or otherwise inferior service to older women 
(Hamberg, 2008; Reyna et al., 2007). This is potentially compounded by persistent stereotypes against the adequacy of plant-based diets (Soifer, 2002).

Those who relied on the Internet for their nutritional information had a more positive view on the availability of health resources with many believing that online offerings were adequate for the needs of older persons. Despite the availability of information online, however, respondents were careful to acknowledge that a person must actively seek out this information. Lack of initiative and wherewithal, both characteristics that are unequally distributed across the population, can thus inhibit access. As one woman explained:

Unless someone actually seeks out information about veganism or plant-based nutrition or has a friend who has enlightened them about it, or see a movie like Forks Over Knives, you know it's those chance encounters. Then they're not going to have the access $[\ldots]$. Uninformed people are subsequently at a disadvantage. This would be problematic for the average person middle-aged or younger person, but even more so for older Americans who are less likely to be computer literate. Indeed, one study confirms that the ability of older women with lower socioeconomic statuses to seek healthcare information online is regularly impeded by unfamiliarity with technology, perceived uselessness of internet research, and financial cost (Bowen, Meischke, Bush, Wooldridge, Robbins, Ludwig, \& Escamilla, 2010). That many of our respondents hailed from the middle-class could explain their propensity for agential sleuthing.

\section{Evidence for Resilience}

While many of the women reported a negative reception with peers and healthcare providers regarding their vegan lifestyle, there were many who felt they had gained selfconfidence and a deepening commitment to their values as they aged. This contradicts with research on the general population which finds that age is negatively correlated with self-esteem 
(McMullin \& Cairney, 2004) and optimistic perceptions of aging (especially for women) (Yaghoobzadeh et al., 2017). Age, for some of our vegans, can be an asset and source of empowerment. Indeed, one in four respondents believed that their age granted them strength on their vegan path. For many, this aided them in resisting judgments received: "In general, as we get older, we feel more confident in our choices anyway, and less compromised and indecisive in situations. And generally, more likely to stand up for what we believe and follow through in what we believe in." This resilient perspective proves useful in combating pressure to conform, especially as research shows that one of the main reasons for high vegan recidivism is the social discomfort associated with the adoption of an uncommon lifestyle (Asher et al., 2014). This finding also contrasts with the tribulations they perceive that younger vegans face. Consider the comments of one woman who compared herself with her younger co-workers who were once vegan but had recidivated:

At one point, one of them said that it was peer pressure and I can understand that. And they are both younger than me, they're both in their 30s, so maybe being older [ . . . I I guess when you're my age, I'm a senior, so I don't think I am going to be challenged in the same way that someone a lot younger may be about it. Because it's sort of like you know she's going to be the way she is going to be because she is older and if somebody is a lot younger, there might be the idea that you can change them somehow.

Despite the smaller number of older vegans, the glorification of youth in vegan media, and the hostility emitted from nonvegan family and friends. These women are committed to their values. Although age discrimination may flicker in the background, many participants actually see age working to their advantage. To them, it is an accepted and appreciated social identity.

These strategies of resistance are supported by research of older women combatting 
stereotypes of fragility in other community organizations as well (Grenier \& Hanley, 2007). Age, in other words, can be an asset. That said, we must consider that the higher than average socioeconomic status enjoyed by most vegans (Maurer, 2002) (many of our participants included) could account for this resilience. Indeed, researchers find that the psychological wellbeing and confidence of older adults is correlated with possession of health and wealth (Yaghoobzadeh et al., 2017). It is also the case, however, that our participants' connection to the vegan community is believed to contribute to their overall psychological wellbeing. This would not be surprising given that the importance of social integration for healthful, happy aging is well-documented in the medical literature (Li et al., 2018).

\section{Conclusion}

Although our data are limited and participant consciousness to identity barriers was wavering, we can venture to suggest that older vegan women in this study face exceptional hardships related to their veganism, particularly with regard to representation in the vegan movement and the accessibility of healthcare resources. These findings are consistent with vegan feminism's assertion that individuals face unique privileges or underprivileges resulting from multiple intersecting identities. Our participants were more likely to have adopted veganism late in life, and over half had maintained the lifestyle for at least five years. This evidence undermines the stereotype of veganism as primarily a youth interest. Rather, it supports existing social movement research, limited though it may be, which finds a positive correlation between age and activism (Rupp, 2001; Valiente, 2015). That said, older vegans are a minority in the movement, dominated as it is by millennials, and some of our participants sensed this. The representation of their demographic in vegan spaces is, from their perspective, minimal and frequently objectifying. 
Otherwise, our participants heavily aligned with the collective vegan identity to reinforce their group belonging. Their responses highlighted problems shared by the larger vegan community, generally overlooking any added difficulties that may be attributed to their age and gender identities. Thus, while we predicted that the vegan movement would exhibit an intersectional failure with regard to age, older vegan women themselves did not necessarily acknowledge their marginalization. For instance, the dietary motivations of most older vegan women in our study mostly relate to their support for Nonhuman Animal rights, as is typical of the general vegan population. Another commonality is the strain they experience in nonvegan social networks. Because veganism works as an additional minority status (Greenebaum, 2016; Markowski \& Roxburgh, 2019), our participants, like other vegans, negotiate stigma and societal resistance by constructing boundaries amid their nonvegan networks.

Disrupted social integration could, however, prove a greater harm for older persons who are more vulnerable to isolation. These findings support informal research conducted by The Vegan Society whereby older vegans (especially those who were not internet savvy) worried of becoming isolated (Henderson, 2012). Older vegans share this heightened vulnerability to isolation with older LGBTQIA+ individuals who must also negotiate a stigmatized and marginal identity in a community that privileges youth. Preliminary research on the experiences of older LGBTQIA+ folks emphasizes the importance of relationships and social connection in aging well (Muraco, 2017). Continued social movement participation can counter this difficulty given its therapeutic effects and its propensity to build social capital (McHugh, 2012).

Another exception to the age-neutral vegan experience that was identified in The Vegan Society's survey (Henderson, 2012) was the difficulty that olders face in obtaining vegan medicine. Although this problem did not surface in our results, some of our respondents did 
indicate that they were challenged by skeptical healthcare providers. This is a problem that disproportionately impacts older persons who have greater medical concerns as they age. Due to the lack of societal support for their vegan lifestyle, our participants reported having to consciously seek out information online to substitute for their doctor's advice. This propensity for initiative and independence related to another key finding: many women cited their age as a source of considerable confidence which supported and sustained their veganism. In a society that is hostile to veganism, older age is thought to bring with it a greater maturity and steadfastness. Although ageism creates social stigma against old age (Widrick \& Raskin, 2010), old age appears to buffer vegan stigma.

Some design limitations restricted the generalizability of this exploratory data. Participants were asked questions about age, gender, and vegan identity without the luxury of advance preparation. Our questions asked participants to consider multiple connections related to how their gender and age are received in the social space; this proved difficult for those participants who had little to no experience thinking intersectionally. Additional survey-based research with open-ended answers might solicit less harried responses. One third of our respondents did have thoughts on the intersection of gender and species, which we suspect is due to the influence of vegan feminist theory in the vegan movement. ${ }^{9}$ Further research on the role of age in this intersection would likely develop the activist consciousness similarly.

Additional research of this kind is recommended for at least two reasons. First, as the vegan movement struggles to diversify in its effort to grow its political and cultural influence, ageism is likely to challenge the movement's capacity for inclusivity and resonance. The dearth of research on vegan aging, we argue, stands as a strategic oversight. Second, this lack of

\footnotetext{
${ }^{9}$ Vegan feminist theory was established by activist-scholars who have deep connections to the movement. As Adams \& Gruen (2014) record, this theory has been shaping the activist imagination since the early 1980s.
} 
attention to vegan aging undermines the vegan movement's core values of social justice and inclusivity. Lorde warns, "There is a pretense to a homogeneity of experience covered by the word sisterhood that does not, in fact, exist" (2017, p. 18). We thus conclude by restating vegan feminism's position on social movement epistemology: recognizing and honoring difference among humans and nonhumans alike is key to challenging oppression. This premise holds true not only for the movement's constituents, but the movement's own participants. Because American veganism is so heavily gendered and gender is so greatly influenced by age, advancements in vegan feminist thought will require an intersectional examination of both gender and age concurrently.

\section{Works Cited}

Adams, C. (2003). The pornography of meat. New York, NY: Continuum.

Adams, C., Breitman, P., \& Messina, V. (2014). Never too late to go vegan. New York, NY: The Experiment, LLC.

Adams, C., \& Calarco, M. (2017). Derrida and the sexual politics of meat. In A. Potts (Ed.) Meat culture (pp. 31-53). Leiden, NLD: Brill.

Adams, C. \& Gruen, L. (2014). Ecofeminism. New York, NY: Bloomsbury Publishing, Inc.

Adler, G., Schwartz, J. \& Kuskowski, M. (2005). An exploratory study of older adults’ participation in civic action. Clinical gerontologist, 31(2), 65-75.

Allcorn, A. \& Ogletree, S. (2018). Linked oppression. Feminism and psychology. Online first. Angus, J. \& Reeve, P. (2006). Ageism. Journal of applied gerontology, 25(2), 137-152. Applewhite, A. (2016). This chair rocks. Farmington Hills, MI: Thorndike Press. Asher, K., Green, C., Gutbrod, H., Jewell, M., Hale, G., \& Bastian, B. (2014, December). Study 
of current and former vegetarians and vegans. Retrieved from https://faunalytics.org/study-of-current-and-former-vegetarians-and-vegans/

Bowen, D., Meischke, H., Bush, N., Wooldridge, J., Robbins, R., Ludwig, A., \& Escamilla, G. (2010). Predictors of women's internet access and internet health seeking. Health care for women international, 24(10), 940-951.

Bresnahan, M., J. Zhuang, \& X. Zhu. (2016). Why is the vegan line in the dining hall always the shortest? Stigma and health, 1(1), 3-15.

Butler, R. (1975). Why Survive? New York, NY: Harper \& Row Publishers.

Calvert, S. (2014, August 11). Ripened by human determination. Retrieved from https://www.vegansociety.com/sites/default/files/uploads/Ripened\%20by $\% 20$ human $\% 20$ determination.pdf

Cherry, E. (2006). Veganism as a cultural movement. Social movement studies, 5(2), 155-170.

Chrisler, J., Barney, A., \& Palatino, B. (2016). Ageism can be hazardous to women's health. Journal of social issues, 72(1), 86-104.

Clark, V. (2005). Dietary disrespect — the end is in sight. The vegan, Autumn, 16-17.

Cole, M. \& Morgan, K. (2011). Veganphobia: Derogatory discourses of veganism and the reproduction of speciesism in UK national newspapers. The British journal of sociology, 62(1), 134-153.

Corbett, J. (2014, March 14). Respecting needs of older vegetarians and vegans in the care sector 'is a matter of human rights and equality in all areas' Retrieved from https://www.homecare.co.uk/news/article.cfm/id/1562834/respecting-needs-oldervegetarians-and-vegans-care-sector-matter-of-human-rights-and-equality Crenshaw, K. (2016, March 14). On intersectionality. Women of the world festival. Retrieved from 
https://www.youtube.com/watch?v=-DW4HLgYPlA

Deckha, M. (2008). Disturbing images. Ethics and environment 13(2), 35-76.

Draper, P. (2005). Patronizing speech to older patients. Reviews in clinical gerontology, 15(3-4), 273-279.

Foster, J. (2018). In keeping with family tradition. Qualitative sociological review, 24(1), 6-28.

Freeman, C. (2014). Framing Farming. New York, NY: Rodopi.

Gaard, G. (1993). Ecofeminism. Philadelphia, PA: Temple University Press.

Gaarder, E. (2011). Women and the animal rights movement. New Brunswick, NJ: Rutgers University Press.

Gambert, I. \& Linné, T. (2018). From rice eaters to soy boys: race, gender, and tropes of 'plant food masculinity.' Animal studies journal, 7(2), 129-179.

Gordon, H. (2007). Allies within and without. Journal of contemporary ethnography, 36(6), 631668.

Graça, J., Calheiros, M., Oliveira, A., \& Milfont, T. (2018). Why are women less likely to support animal exploitation than men? Personality and individual differences, 129, 66-69.

Greenebaum, J. (2016). Questioning the concept of vegan privilege. Humanity \& society, 41(3), 355372.

Grenier, A. \& J. Hanley. (2007). Older women and 'frailty.' Current sociology, 55(2), 211-228.

Hamberg, K. (2008). Gender bias in medicine. Women's health, 4(3), 237-243.

Harper, B. (2010). Race as a 'feeble matter' in veganism. Journal of critical animal studies, 8(3), 527.

Henderson, J. (2008). Issues in the medical treatment of elderly women. Journal of women \& aging, $9(1-2), 107-115$. 
Henderson, R. (2011). Vegan care homes for the elderly. The vegan, fall, 14-15.

------. (2012). Vegan advocacy. The vegan, summer, 13.

Holstein, M. (2015). Women in late life. Lanham, Maryland: Rowman \& Littlefield Publishers.

Hummert, M., J. Shaner, T. Garstka, \& C. Henry. (1998). Communication with older adults. Human communication research, 25(1), 124-151.

Janssen, M., Busch, C., Rödiger, M., \& Hamm, U. (2016). Motives of consumers following a vegan diet and their attitudes towards animal agriculture. Appetite, 105, 643-651.

Katz, S. \& Laliberte-Rudman, D. (2004). Exemplars of retirement. In E. Tulle (Ed.), Old age and agency (pp. 45-65). New York, NY: Nova Science Publishers, Inc.

Ko, A. \& Ko, S. (2017). Aphro-ism: essays on pop culture, feminism, and Black veganism from two sisters. New York, NY: Lantern Books.

Kretzer, M. (2016, April 1). Could PETA’s prank lead to a naked Oprah ad? Retrieved from https://www.peta.org/blog/o-what-a-surprise/

Li, S., Hagan, K., Grodstein, F., \& VanderWeele, T. (2018). Social integration and healthy aging among U.S. women. Preventative medicine reports, 9, 144-148.

Lorde, A. (2017). Age, race, class, and sex. In B. Scott, S. Cayleff, A. Donadey, \& I. Lara (Eds.), Women in culture (pp. 16-22). Malden, MA: John Wiley \& Sons, Ltd.

Macmanus, S. \& Tenpas, K. (1998). The changing political activism patterns of older Americans. In J. Steckenrider and T. Parrott (Eds.), New directions in old-age policies (pp. 111-130). Albany, NY: State University of New York Press.

MacNair, R. (1998). The psychology of becoming a vegetarian. Vegetarian nutrition, 2(3), 96-102.

-----. (2001). McDonald's 'Empirical look at becoming vegan.' Society \& animals, 9(1), 63-69.

Mangels, R., Messina, V., \& Messina, M. (2012). The dietitian's guide to vegetarian diets. Sudbury, 
MA: Jones \& Bartlett Learning.

Markowski, K. and Roxburgh, S. (2019). "If I became a vegan, my family and friends would hate me:” Anticipating vegan stigma as a barrier to plant-based diets. Appetite, 135, 1-9.

Maurer, D. (2002). Vegetarianism. Philadelphia, PA: Temple University Press.

McMullin, J. \& Cairney, J. (2004). Self-esteem and the intersection of age, class, and gender. Journal of aging studies, 18(1), 75-90.

McHugh, M. (2012). Aging, agency, and activism. Women \& therapy, 35(3-4), 279-295.

Muraco, A. (2017). Aging with pride. Sex \& gender news, July, 9-10.

Pendergrast, N. (2014). A sociological examination of the contemporary animal advocacy movement. Dissertation. Perth: Curtin University.

Pendergrast, N. (2018). PETA, patriarchy and intersectionality. Animal studies journal, 7(1), 59-79.

Reyna, C., Goodwin, E., \& Ferrari, J. (2007). Older adult stereotypes among care providers in residential care facilities. Journal of gerontological nursing, 33(2), 50-55.

Reynolds, E. (2017, February 15). In America, aging while Black takes solidarity, activism and magic. Huffpost. Retrieved from https://www.huffingtonpost.com/entry/agingwhile-black-activism us 58a477efe4b094a129f106eb

Rodger, G. (2002). Interview with Donald Watson. Retrieved from: https://www.vegansociety.com/sites/default/files/DW_Interview_2002_Unabridged_Tran script.pdf

Rupp, L. (2001). Is feminism the province of old (or middle-aged) women? Journal of women's history, 12(4), 164-173.

Sabik, N. (2015). Ageism and body esteem. The journal of gerontology, 70(2), 189-1999.

Sawchuk, D. (2009). The raging grannies: defying stereotypes and embracing aging through 
activism. Journal of women \& aging, 21(3), 171-185.

Seidman, I. (2013). Interviewing as qualitative research. New York, NY: Teachers College Press.

Sharpe, P. (2008) Older women and health services. Women \& health, 22(3), 9-23.

Shprintzen, A. (2013). The vegetarian crusade. Chapel Hill, NC: The University of North Carolina Press.

Soifer, S. (2002). Vegan discrimination. Loyola of Los Angeles law review, 36(4), 1708-1732.

Taylor, N. and Fraser, H. (2018). Resisting sexism and speciesism in the social sciences. Gender, work \& organization. Online first.

The Vegan Society. (n.d.). Definition of veganism. Retrieved from: https://www.vegansociety.com/go-vegan/definition-veganism

The Vegan Society. (2016). How many vegans live in Britain. The vegan, 3, 13.

Twine, R. (2010). Intersectional disgust? Feminism \& psychology, 20(3), 397-406.

Twine, R. (2017). Negotiating social relationships in the transition to vegan eating practices. In A. Potts (Ed.), Meat culture (pp. 243-263). Leiden, NLD: Brill.

Valiente, C. (2015). Age and feminist activism. Social movement studies, 14(4), 473-492.

Vasil, L. \& Wass, H. (2006). Portrayal of the elderly in the media. Educational gerontology, 19(1), 71-85.

Vegetarian Resource Group. (2016). How many adults in the U.S. are vegetarian and vegan? Retrieved from http://www.vrg.org/nutshell/Polls/2016_adults_veg.htm

Walz, T. (2002). Crones dirty old men, sexy seniors. Journal of aging and identity, 7(2), 99-112.

Wells, J., \& Dumbrell, A. (2006). Nutrition and aging. Clinical interventions in aging, 1(1), 67- 
79.

Whitbourne, S. \& Hulicka, I. (1990). Ageism in undergraduate psychology texts. American psychologist, 45(10), 1127-1136.

Widrick, R. \& Raskin, J. (2010). Age-related stigma and the golden section hypothesis. Ageing \& mental health, 14(4), 375-385.

Wright, L. (2015). The vegan studies project. Athens, GA: University of Georgia Press.

Yaghoobzadeh, A., Nia, H., Sharif, S., Hosseinigolafshani, S., Mohammadi, F., Oveisi, S., \&

Allen, K. (2018). Role of sex, socioeconomic status, and emotional support in predicting aging perception among older adults. The international journal of aging and human development, 87(1), 77-89. 